\title{
Association of Daily Home-Based Hot Water Bathing and Glycemic Control in Ambulatory Japanese Patients with Type 2 Diabetes Mellitus During the COVID-19 Pandemic: A Multicenter Cross-Sectional Study
}

This article was published in the following Dove Press journal: Diabetes, Metabolic Syndrome and Obesity: Targets and Therapy

\author{
Hiroharu Kamioka' \\ Yasunori Mori ${ }^{2}$ \\ Takahiko Horiuchi (D) ${ }^{3}$ \\ Takahito Hayashi ${ }^{4}$ \\ Koichiro Ohmura ${ }^{5}$ \\ Satoru Yamaguchi ${ }^{6}$ \\ Mitsutoshi Kato ${ }^{7}$ \\ 'Faculty of Regional Environment Science, \\ Tokyo University of Agriculture, Tokyo, \\ Japan; ${ }^{2}$ Mie Prefecture Health and \\ Environment Research Institute, \\ Yokkaichi, Mie, Japan; ${ }^{3}$ Department of \\ Internal Medicine, Kyushu University \\ Beppu Hospital, Beppu, Oita, Japan; \\ ${ }^{4}$ Department of Legal Medicine, \\ Graduate School of Medical and Dental \\ Sciences, Kagoshima University, \\ Kagoshima, Japan; ${ }^{5}$ Department of \\ Rheumatology and Clinical Immunology, \\ Kyoto University Graduate School of \\ Medicine, Kyoto, Japan; ${ }^{6}$ Department of \\ Oriental Medicine, Saitama Medical \\ University, Saitama, Japan; ${ }^{7}$ Kato Clinic of \\ Internal Medicine, Tokyo, Japan
}

Correspondence: Hiroharu Kamioka Faculty of Regional Environment Science, Tokyo University of Agriculture, I-I-I Sakuragaoka, Setagaya-Ku, Tokyo I568502, Japan

Tel/Fax +8I 354772587

Email hlkamiok@nodai.ac.jp
Purpose: To clarify the relationship between daily hot water bathing (HWB) at home and glycemic control in middle-aged and elderly ambulatory patients with type 2 diabetes mellitus (T2DM).

Methods: We defined hemoglobin A1c (HbA1c) as the main outcome. We set $7.0 \%$ based on the mean value of the dependent variable as the cut-off point for analysis. Frequency of HWB was an explanatory variable. A two-sample $t$-test was used to compare between groups with continuous variables. Multiple logistic regression analysis was performed for frequency, adjusted age, sex, BMI, T2DM duration (Model 1), and other confounding factors (Model 2). Odds ratio (OR) and 95\% confidence interval (95\% CI) were calculated.

Results: Among 838 patients, there was a significant difference $(p<0.001)$ in age between males ( $n=528,62.8 \pm 8.7$ years) and females $(n=310,65.0 \pm 8.1$ years). In Model 1 , compared with participants who used HWB more than seven times a week, those with poorly controlled HbA1c were significantly associated with low frequency of HWB: four to six times a week (OR 1.32, 95\% CI 0.87-1.99) and less than three times a week (OR 1.43, 95\% CI 0.98-2.10); p-value for overall trend was 0.041. In Model 2, p-value for overall trend was 0.138.

Conclusion: A higher frequency of HWB was moderately associated with a decreased risk of poor glycemic control in middle-aged and elderly ambulatory patients with T2DM.

Keywords: hot water bathing, type 2 diabetes, hemoglobin A1c, middle-aged and elderly ambulatory patients

\section{Introduction}

Since the 1980 s, the proportion of people with diabetes mellitus (DM) in populations worldwide has considerably increased, making this disease the focus of global health initiatives. ${ }^{1}$ In 2010 , the fifth leading risk for death was having a high fasting glucose level, ${ }^{2}$ while $6.8 \%$ of excess deaths were associated with DM. $^{3}$ The International Diabetes Federation predicted that prevalence of metabolic disorders by 2035 would be nearly 600 million cases. ${ }^{4}$ In contrast, a recent systematic review (SR) reported that the incidence of DM (primary diagnoses DM) rose between the 1990s and mid-2000s, and has levelled off or decreased. ${ }^{5}$ The rate may have flattened due to the implementation of preventive strategies as well as public health 
education and awareness campaigns, highlighting the effectiveness of worldwide campaigns in curbing the DM epidemic.

Since 2019, COVID-19 has become a deadly foe for human beings. Investigations of co-morbidities in hospitalized patients with COVID-19 have identified DM as an important risk factor for mortality and the progression to acute respiratory distress syndrome. ${ }^{6}$ Among 5700 hospitalized patients with COVID-19 in New York City, one of the most common comorbidities was DM ( $\mathrm{n}=1808,33.8 \%){ }^{7}$ Another study reported that patients with DM had a significantly increased risk of intensive care unit admission (odds ratio 2.79, 95\% confidence interval 1.85-4.22, $p<0.0001$ ) and mortality (odds ratio $3.21,95 \%$ confidence interval $1.82-5.64, p<0.0001){ }^{8}$ Furthermore, many cases of DM (21\%) were found in autopsies of COVID-19-related deaths. ${ }^{9}$

The prevention and management of DM continues to be a common challenge in most countries. The most important indicator for the efficacy of DM management in patients with type 2 (T2) DM is glycemic control. ${ }^{10}$ Glycosylated hemoglobin $(\mathrm{HbA} 1 \mathrm{c})$ is recognized as a gold standard for the diagnosis of DM. ${ }^{11}$ It is well known that the risk of irreversible micro- and macrovascular complications, such as neuropathy, nephropathy, retinopathy, and cardiovascular diseases, is increased with poor glycemic control. ${ }^{12,13}$ An HbAlc level $>7 \%$ is defined as poor control, ${ }^{14}$ with $6.5 \%$ as the recommended cut-off point for diagnosing diabetes. ${ }^{11}$

Along with diabetes education, diet modification, and lifestyle changes, more adjunct therapeutic modalities are increasingly being used to manage T2DM. ${ }^{13,15,16}$ These interventions may attenuate or even reverse the complications associated with T2DM. However, in spite of the benefits of these interventions, compliance may be poor or even impossible. Together with lifestyle interventions, drug therapy may be prescribed but may come with unfortunate side effects. ${ }^{17}$

Some non-pharmaceutical interventions that have few side effects and are easily accepted by patients include balneotherapy and spa therapy. ${ }^{18}$ Several SRs with metaanalysis reported that these interventions may have a painrelief effect and improve the quality of life in patients. ${ }^{18-22}$

Passive heating such as hot water bathing may benefit people with DM and those with poor glycemic control. This well-known viewpoint was reported by Hooper two decades ago. ${ }^{23}$ Eight subjects with T2DM underwent an intervention in which they sat in warm water $\left(38^{\circ} \mathrm{C}-41^{\circ} \mathrm{C}\right)$ for 30 minutes a day, 6 days a week, over 3 weeks. At the end of the 3 weeks, their fasting glucose was reduced, but more importantly, HbA1c was also reduced by $1 \%$.
Many other clinical trials and in vivo experiments have been conducted to explore relationships between the heat environment and glycemic control. Resting in passive heating environments may induce hormonal changes that could, in turn, influence glycemic control. ${ }^{24}$ Higher levels of hormones, such as growth or thyroid hormones, and noradrenaline, and adrenaline levels may lead to higher concentrations of blood glucose. ${ }^{25-27}$ An acute increase in blood glucose concentration is not beneficial, but passive heating may cause other changes that lower the blood glucose concentration. Within muscles, temperature and blood flow can increase in the presence of adequate heating, and lead to an acute increase in muscle glucose uptake $^{28,29}$ Furthermore, heat shock proteins (HSPs) are an important mechanism for glycemic control. ${ }^{30}$ Physiological stress such as heat is accompanied by a heat shock response, which triggers the release of HSP.

Hot water bathing (HWB) in temperatures from 38 to $42^{\circ} \mathrm{C}$ is a typical passive heating activity and is a common practice in Japan. A cross-sectional study in Japan demonstrated that bathing in a bathtub every day or more frequently was associated with a good state of self-rated health and sleep quality. ${ }^{31}$ On the other hand, a recent cross-sectional study in Japan reported that approximately $70 \%$ of people take a bath every day (seven times a week), but the rest do not utilize bathing, and approximately 3\% actually have no bathing habit. ${ }^{32}$ The effectiveness of regular HWB on glycemic control has not been thoroughly investigated in epidemiological (observational) studies. However, in view of the studies described above, it is hypothesized that good glycemic control in patients with T2DM is associated with frequent HWB.

The purpose of the present study was to clarify the relationship between daily HWB at home and glycemic control in middle-aged and elderly ambulatory patients with T2DM.

\section{Methods}

\section{Participants}

The Japanese Society of Balneology, Climatology and Physical Medicine certifies specialists from doctors. As of 26 February 2020, 1018 doctors were certified through this system in Japan (Figure 1).

In the present study, an email outlining the research protocol was sent to all doctors. The email requested information on ambulatory patients during the period 1-14 June, 2020 at each medical institution. Each doctor 


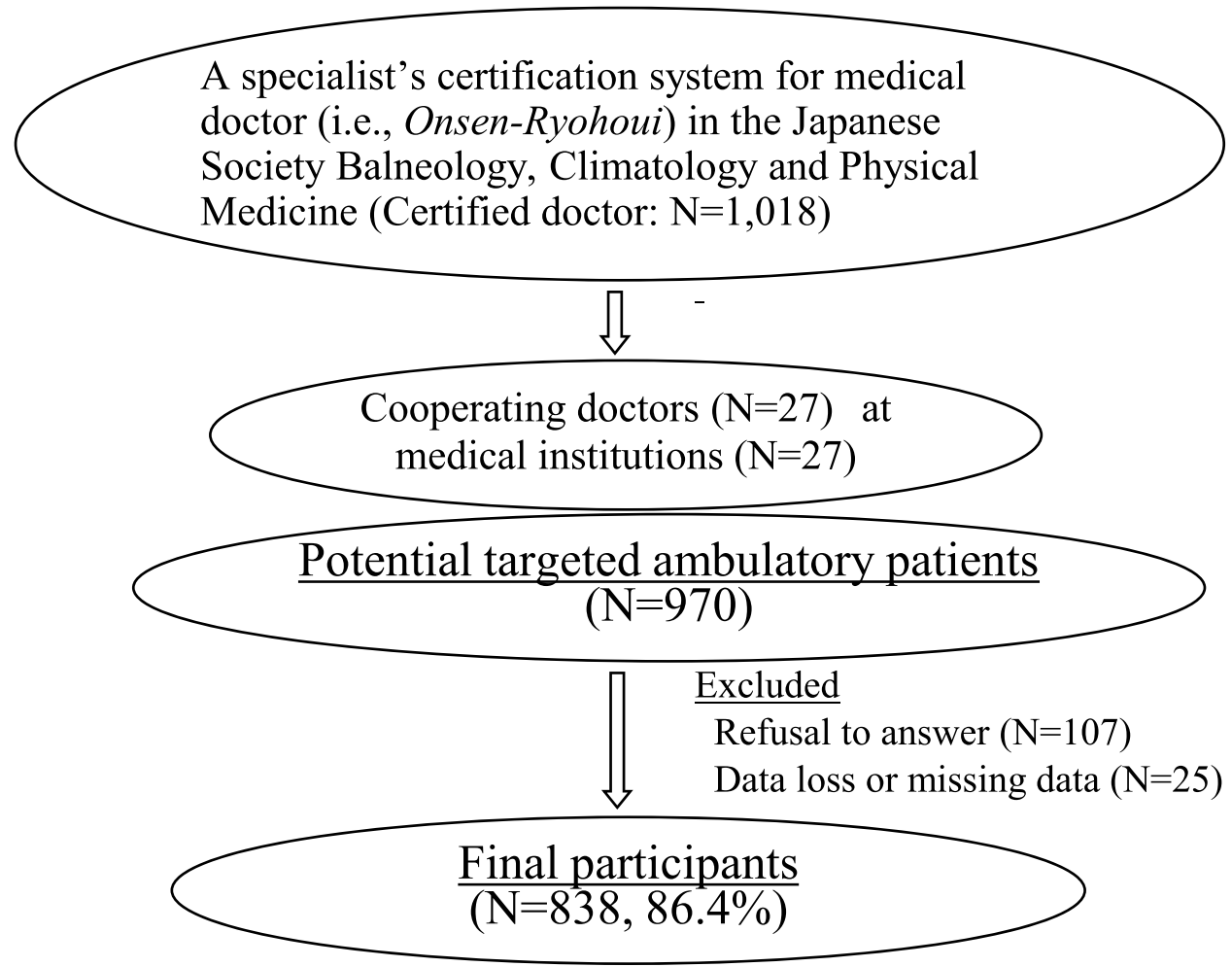

Figure I Participant recruitment.

was eligible to receive credits toward the renewal of their specialist certification. In response, 27 doctors (27 medical institutes) accepted the invitation to be a part of the study by the deadline of 15 May 2020. The sample size was not calculated because this was a multicenter cross-sectional study.

Ambulatory patients, between 40 and 75 years of age who were being treated by Society doctors during the period 1-7 June, 2020, were enrolled. The study included patients living independently at home but excluded those who were care-receivers with no self-help or who were hospitalized. The participants were required to have a history of at least 3 months of hospital visits with T2DM. The duration of T2DM, presence of complications and other underlying illnesses, and types of medications used were not included in the criteria for exclusion.

Of 970 potential ambulatory patients, 863 were interviewed for the study while 107 declined (Figure 1). After excluding 25 patients with missing data, a total of 838 patients $(86.4 \%)$ had data that was valid for analysis.

\section{Study Design}

This multicenter cross-sectional study included ambulatory patients who were being treated by Society doctors.
The Strengthening the Reporting of Observational Studies in Epidemiology (STROBE) statement formed the basis of the study's procedures, analysis, and description. ${ }^{33}$ This study was performed and funded by the Academic Committee, Japanese Society of Balneology, Climatology and Physical Medicine as a special research project.

\section{Primary Outcome: HbAlc as an Indicator of Glycemic Control Status}

We set HbAlc as the primary outcome and dependent (criterion) variable. A secondary outcome was not set.

After the patient was initially treated for T2DM in an examination room, doctors recorded information directly on an interview sheet while reviewing medical records and listening to the patient. The total time for recording this information was approximately 1 to 2 minutes.

\section{Definition of Daily Hot Water Bathing at Home}

Daily hot water bathing was defined as soaking in the bathtub, using either normal tap or hot spring water. We did not define temperature ranges for hot water. 


\section{Primary Explanatory Variables}

Together with $\mathrm{HbA1c}$, we defined frequency and duration in daily HWB as explanatory variables. Doctors who conducted patient interviews recorded this information.

\section{Covariates}

After the patient was initially treated for their underlying disease in an examination room, the doctor recorded information directly on the interview sheet while reviewing medical records and listening to the patient. The total time for recording this information ranged from 1 to 3 min (Figure 2). Doctors recorded sex, age, height, weight, Body Mass Index (BMI), T2DM duration, alcohol consumption status, meal modification status, smoking status, and exercise status on the questionnaire form. With regard to the spread of COVID-19, a lack of exercise is one of the serious problems in glycemic control. For exercise status, the average number of steps per day was used.

Based on medical records, doctors recorded the patients' oral and injected medications. The list of oral medicines included biguanide medicine, thiazolidinediones, sulfonylureas, insulin secretion promoting agents, dipeptidyl peptidase- 4 inhibitors, $\alpha$-glucosidase inhibitors, and sodium glucose transporter 2 inhibitors. Injected medicines included insulin and glucagon-like peptide 1 receptor agonists.

In addition, the presence of sick days, dizziness, and impaired consciousness associated with hypoglycemia were also examined.

In clinical practice, the time spent with a patient is extremely short and it was therefore ethically problematic to place an extra burden of time on doctors. Furthermore, we postulated that fewer doctors would participate as the number of items increased and the survey became more complicated. As a result, and since feasibility was the priority of this study, we did not survey other items (eg, accurate daily energy intake or consumption, or occurrence of other underlying diseases).

\section{Ethical Considerations and Clinical Trial Registration}

This study was conducted in accordance with the Declaration of Helsinki. A checked-style type of informed consent was used in order to reduce the mental and physical burden on patients. Patients initially presented because they had symptoms such as pain or other types

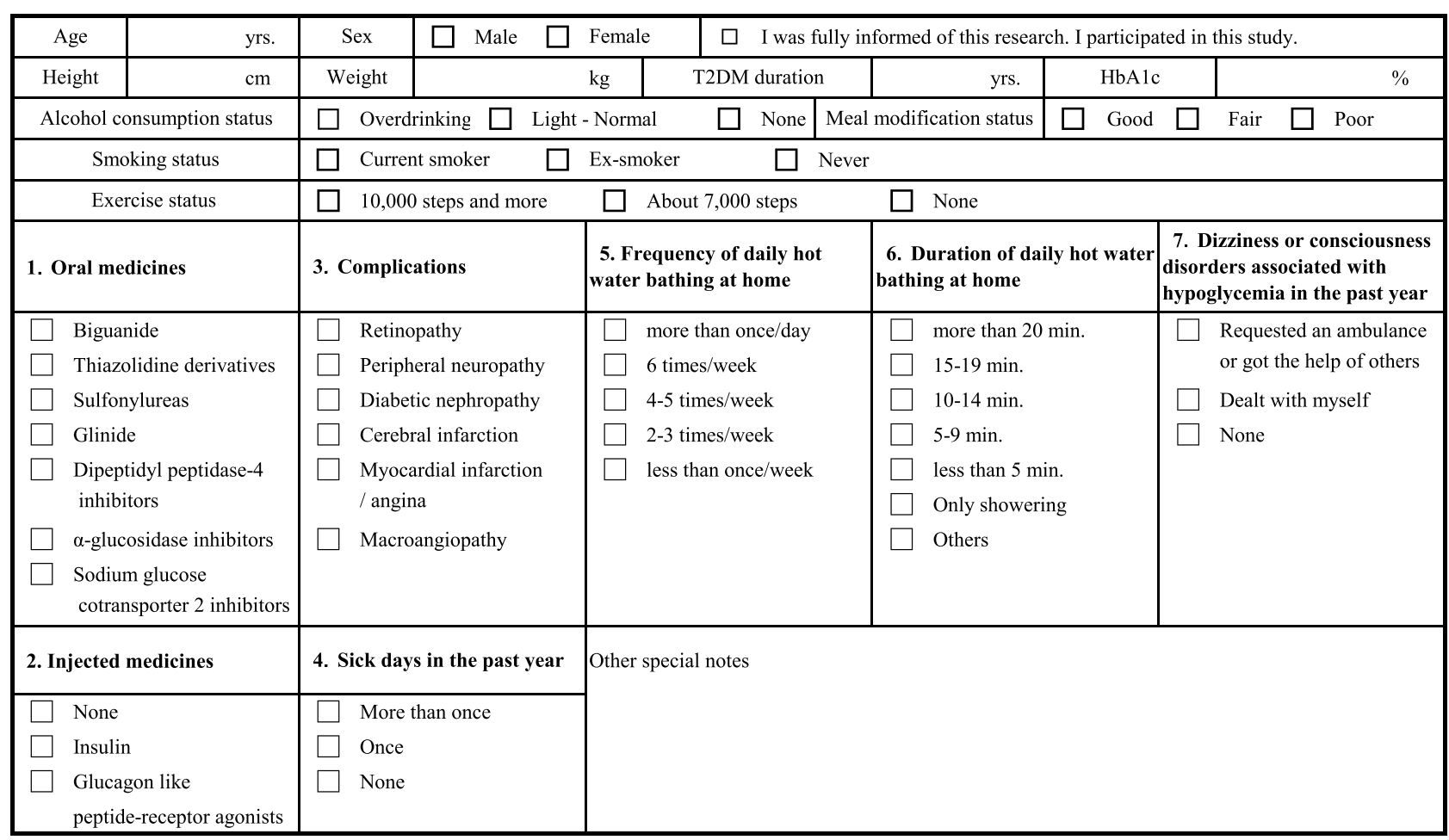

Figure 2 Survey sheet actually used: Questionnaire content and data extraction sheet from medical records (translated version from Japanese to English). A manual for doctors was available. 
of discomfort. The study methodology (protocol) was established on 17 February 2020 and was approved by the Ethics Board of Tokyo University of Agriculture (No.1922 in 2020).

The study was registered as UMIN000039603 by the University Hospital Medical Information Network Clinical Trials Registry (UMIN-CTR) in Japan (refer: https:// upload.umin.ac.jp/cgi-open-bin/ctr e/ctr view.cgi? recptno $=\mathrm{R} 000045162$ ).

\section{Statistical Analysis}

A two-sample $t$-test was used to compare between groups with continuous variables. A $\chi^{2}$ test was used for discrete variables.

The association between frequency and duration of HWB was the explanatory variable and HbA1c was the dependent variable. A multiple logistic regression analysis was performed for each frequency, duration, sex, adjusted age, and other explanatory variables. We set " $7.0 \%$ and more versus $7.0 \%$ and less" based on the mean value of the dependent variable as the cut-off point for analysis. When the value was greater than $7.0 \%$, it was considered that the patient did not have a properly controlled glycemic status.

Additionally, in order to increase the sensitivity of the multiple logistic model, integration was performed in three categories for each explanatory variable. Odds ratios (OR) and $95 \%$ confidence intervals $(95 \% \mathrm{CI})$ were calculated. Subgroup analysis was not planned.

IBM SPSS Statistics 20.0 (IBM Corporation, Armonk, NY, USA) and EZR (Saitama Medical Center, Jichi Medical University, Saitama, Japan), ${ }^{34}$ a graphical user interface for $\mathrm{R}$ (The R Foundation for Statistical Computing, Vienna, Austria), were used for statistical analyses. EZR is a modified version of $\mathrm{R}$ commander for statistical functions frequently used in biostatistics. A $P$-value of less than 0.05 was considered statistically significant.

\section{Results}

There was a significant difference $(\mathrm{p}<0.001)$ in age between males $(n=528,62.8 \pm 8.7$ years $)$ and females $(n=310,65.0$ \pm 8.1 years) in this study (Table 1 ). Regarding HbA1c levels, there was no significant difference between males (7.1 $\pm 2.8 \%)$ and females $(6.8 \pm 0.9 \%)$. There was a significant difference $(\mathrm{p}<0.05)$ between males $(12.6 \pm 8.1$ years $)$ and females (11.2 \pm 8.5 years) in T2DM duration. For frequency and duration of HWB, there were no significant differences between sexes; overall $67.7 \%$ of participants immersed in a bathtub filled with hot tap water every day.
There was no significant difference between males (1.8 $\pm 1.2)$ and females $(1.6 \pm 1.1)$ in the use of oral medicines for T2DM, nor was there a significant difference for injected medicines (Table 2). Regarding total number of complications associated with T2DM, there was a significant difference $(\mathrm{p}<0.01)$ between males $(0.7 \pm 0.9)$ and females $(0.5 \pm 0.9)$. No significant differences between the sexes were seen for sick days and dizziness or consciousness disorders associated with hypoglycemia in the past year.

Logistic regression analysis demonstrated that frequency of HWB was moderately associated with HbA1c (Table 3). In the Crude model, compared with participants who used HWB every day (more than equal or seven times a week), those with poorly controlled $\mathrm{HbAlc}$ showed a significant association with a low frequency of HWB: less than three times a week (OR 1.58, 95\% CI 1.10-2.27); the exception was four to six times a week (OR 1.37, 95\% CI 0.92-2.04). The p-value for the overall trend was 0.008. In Model 1, compared with participants who used HWB more than equal or seven times a week, those with the poorly controlled HbAlc showed a moderate association with a low frequency of HWB: four to six times a week (OR 1.32, 95\% CI 0.87-1.99) and less than three times a week (OR 1.43, 95\% CI 0.98-2.10) with a p-value of 0.041 for overall trend. In Model 2, the p-value for overall trend was 0.138 .

Amount of length of HWB was not associated with HbAlc. The p-value for overall trend was $0.208,0.413$, and 0.464 in the Crude model, Model 1, and Model 2, respectively.

\section{Discussion}

This multicenter cross-sectional study is the first to explore the association of daily HWB on glycemic control in middle-aged and elderly ambulatory patients with T2DM during a global COVID-19 pandemic. Study results confirmed that a high frequency of HWB was moderately associated with a decreased risk of poor glycemic control.

\section{Estimated Mechanism of Blood Glucose Control by Resting in Passive Heating Environment: Internal Validity}

The mechanism for blood glucose control by daily HWB (ie, warming the whole body except for the head at about $40^{\circ} \mathrm{C}$ ) may be multi-factorial. Daily HWB can induce changes in thyroid hormone, growth hormone, and noradrenaline and adrenaline concentrations that elicit 
Table I Participant Characteristics

\begin{tabular}{|c|c|c|c|c|}
\hline & \multirow{2}{*}{$\begin{array}{l}\text { Total }(\mathbf{N}=\mathbf{8 3 8}) \\
\text { Mean } \pm \text { SD or } \mathbf{N}(\%)\end{array}$} & \multirow{2}{*}{$\begin{array}{l}\text { Male }(\mathrm{N}=528) \\
\text { Mean } \pm \text { SD or } \mathrm{N}(\%)\end{array}$} & \multirow{2}{*}{$\begin{array}{l}\text { Female }(\mathrm{N}=3 \mathrm{I} \mathbf{0}) \\
\text { Mean } \pm \text { SD or } \mathbf{N}(\%)\end{array}$} & \multirow[t]{2}{*}{$P$-value* } \\
\hline & & & & \\
\hline Age (yrs.) & $63.6 \pm 8.5$ & $62.8 \pm 8.7$ & $65.0 \pm 8.1$ & 0.000 \\
\hline 40-55 & $160(19.1 \%)$ & 117 (22.2\%) & 43 (I3.9\%) & \\
\hline $56-64$ & $215(25.7 \%)$ & 147 (27.8\%) & 68 (21.9\%) & \\
\hline $65-75$ & $463(55.3 \%)$ & $264(50.0 \%)$ & 199 (64.2\%) & \\
\hline Height $(\mathrm{cm})$ & $162.0 \pm 9.1$ & $167.1 \pm 6.3$ & $|53.4 \pm 6|$. & 0.000 \\
\hline Weight (kg) & $67.0 \pm 14.6$ & $71.3 \pm 13.8$ & $59.7 \pm 12.9$ & 0.000 \\
\hline Body mass index (BMI) & $25.4 \pm 4.5$ & $25.5 \pm 4.3$ & $25.3 \pm 4.9$ & 0.552 \\
\hline T2DM duration (yrs.) & $12.1 \pm 8.3$ & $12.6 \pm 8.1$ & $11.2 \pm 8.5$ & 0.015 \\
\hline HbAlc (\%) & $7.0 \pm 2.3$ & $7.1 \pm 2.8$ & $6.8 \pm 0.9$ & 0.158 \\
\hline$\leq 6.4$ & $232(27.7 \%)$ & 134 (25.4\%) & $98(31.6 \%)$ & \\
\hline $6.5-6.9$ & 264 (3I.5\%) & $165(31.3 \%)$ & 99 (31.9\%) & \\
\hline $7.0-7.9$ & $260(31.0 \%)$ & $176(33.3 \%)$ & $84(27.1 \%)$ & \\
\hline $8.0-8.9$ & $61(7.3 \%)$ & $37(7.0 \%)$ & $24(7.7 \%)$ & \\
\hline$\geq 9.0$ & $21(2.5 \%)$ & $16(3.0 \%)$ & $5(1.6 \%)$ & \\
\hline Alcohol consumption status & & & & 0.000 \\
\hline Overdrink & $66(7.9 \%)$ & 65 (12.3\%) & I (0.3\%) & \\
\hline Light - normal & $304(36.3 \%)$ & $243(46.0 \%)$ & 61 (19.7\%) & \\
\hline None & $468(55.8 \%)$ & $220(41.7 \%)$ & $248(80.0 \%)$ & \\
\hline Meal modification status & & & & 0.758 \\
\hline Good & $212(25.3 \%)$ & $138(26.1 \%)$ & 74 (23.9\%) & \\
\hline Fair & $510(60.9 \%)$ & $317(60.0 \%)$ & $193(62.3 \%)$ & \\
\hline Poor & $116(13.8 \%)$ & $73(13.8 \%)$ & $43(13.9 \%)$ & \\
\hline Smoking status & & & & 0.000 \\
\hline Current smoker & $132(15.8 \%)$ & $112(21.2 \%)$ & $20(6.5 \%)$ & \\
\hline Ex-smoker & $288(34.4 \%)$ & $247(46.8 \%)$ & $4 \mathrm{I}(\mathrm{I3.2 \% )}$ & \\
\hline Never & $418(49.9 \%)$ & $169(32.0 \%)$ & $249(80.3 \%)$ & \\
\hline Exercise status & & & & 0.000 \\
\hline 10,000 steps and more & $114(13.6 \%)$ & 87 (16.5\%) & $27(8.7 \%)$ & \\
\hline About 7000 steps & $499(59.5 \%)$ & $319(60.4 \%)$ & $180(58.1 \%)$ & \\
\hline None & $225(26.8 \%)$ & $122(23.1 \%)$ & $103(33.2 \%)$ & \\
\hline Frequency of daily hot water bathing at home & & & & 0.145 \\
\hline Once/day & $567(67.7 \%)$ & $344(65.2 \%)$ & $222(71.6 \%)$ & \\
\hline 6 times/week & $42(5.0 \%)$ & $24(4.5 \%)$ & $18(5.8 \%)$ & \\
\hline 4-5 times/week & 79 (9.4\%) & $58(11.0 \%)$ & $21(6.8 \%)$ & \\
\hline $2-3$ times/week & 98 (11.7\%) & $66(12.5 \%)$ & $32(10.3 \%)$ & \\
\hline Sonce/week & $52(6.2 \%)$ & $36(6.8 \%)$ & $17(5.5 \%)$ & \\
\hline Duration of daily hot water bathing at home & & & & 0.256 \\
\hline$\geq 20 \mathrm{~min}$ & $93(11.1 \%)$ & $52(9.8 \%)$ & $4 \mathrm{I}(13.2 \%)$ & \\
\hline $15-19 \mathrm{~min}$ & $112(13.4 \%)$ & 71 (13.4\%) & $4 \mathrm{I}(\mathrm{I} .2 \%)$ & \\
\hline $10-14 \mathrm{~min}$. & $143(17.1 \%)$ & $91(17.2 \%)$ & $52(16.8 \%)$ & \\
\hline 5-9 min. & $265(31.6 \%)$ & $158(29.9 \%)$ & 107 (34.5\%) & \\
\hline$\leq 5 \mathrm{~min}$ & $142(16.9 \%)$ & 97 (18.4\%) & 45 (14.5\%) & \\
\hline Only showering & $81(9.7 \%)$ & $58(\mathrm{I} I .0 \%)$ & $23(7.4 \%)$ & \\
\hline Others & $2(0.2 \%)$ & $\mathrm{I}(0.2 \%)$ & $\mathrm{I}(0.3 \%)$ & \\
\hline
\end{tabular}

Note: *Comparisons by using $t$-test and $\chi^{2}$-test. 
Table 2 Drugs and Symptoms Associated with Type 2 Diabetes

\begin{tabular}{|c|c|c|c|c|}
\hline & Total $(\mathbf{N}=838)$ & Male $(\mathrm{N}=528)$ & Female $(\mathrm{N}=3 \mid 0)$ & \multirow[t]{2}{*}{$P$-value* } \\
\hline & $\begin{array}{l}\text { Mean } \pm \text { SD or } \\
\text { N (\%) }\end{array}$ & $\begin{array}{l}\text { Mean } \pm \text { SD or } \\
\text { N (\%) }\end{array}$ & $\begin{array}{l}\text { Mean } \pm \text { SD or } \\
\text { N (\%) }\end{array}$ & \\
\hline \multicolumn{5}{|l|}{ Oral medicines } \\
\hline Biguanide & 409 (48.8\%) & 255 (48.3\%) & 154 (49.7\%) & 0.753 \\
\hline Thiazolidine derivatives & $72(8.6 \%)$ & $45(8.5 \%)$ & $27(8.7 \%)$ & 1.000 \\
\hline Sulfonylureas & 129 (I5.4\%) & $92(17.4 \%)$ & 37 (II.9\%) & 0.043 \\
\hline Glinide & $37(4.4 \%)$ & $29(5.5 \%)$ & $8(2.6 \%)$ & 0.071 \\
\hline Dipeptidyl peptidase-4 inhibitors & $427(51.0 \%)$ & $264(50.0 \%)$ & $163(52.6 \%)$ & 0.516 \\
\hline$\alpha$-glucosidase inhibitors & $93(11.1 \%)$ & $57(10.8 \%)$ & $36(11.6 \%)$ & 0.803 \\
\hline Sodium glucose cotransporter 2 inhibitors & $26 \mid(31.1 \%)$ & $187(35.4 \%)$ & 74 (23.9\%) & 0.001 \\
\hline Total number of medicines & $1.7 \pm 1.2$ & $1.8 \pm 1.2$ & $1.6 \pm 1.1$ & 0.074 \\
\hline \multicolumn{5}{|l|}{ Injected medicines } \\
\hline None & $604(72.1 \%)$ & $368(69.7 \%)$ & $236(76.1 \%)$ & 0.054 \\
\hline Insulin & $172(20.5 \%)$ & $118(22.3 \%)$ & $54(17.4 \%)$ & 0.106 \\
\hline Glucagon like peptide-receptor agonists & $98(11.7 \%)$ & $65(12.3 \%)$ & $33(10.6 \%)$ & 0.540 \\
\hline \multicolumn{5}{|l|}{ Complication } \\
\hline Retinopathy & 133 (15.9\%) & $90(17.0 \%)$ & $43(13.9 \%)$ & 0.264 \\
\hline Peripheral neuropathy & $128(15.3 \%)$ & $82(15.5 \%)$ & $46(14.8 \%)$ & 0.866 \\
\hline Diabetic nephropathy & $163(19.5 \%)$ & $122(23.1 \%)$ & $4 \mathrm{I}(13.2 \%)$ & 0.001 \\
\hline Cerebral infarction & $46(5.5 \%)$ & $30(5.7 \%)$ & $16(5.2 \%)$ & $0.87 I$ \\
\hline Myocardial infarction / angina & 40 (4.8\%) & $35(6.6 \%)$ & $5(1.6 \%)$ & 0.002 \\
\hline Macroangiopathy & $12(1.4 \%)$ & $6(1.1 \%)$ & $6(1.9 \%)$ & 0.523 \\
\hline Total number of complications & $0.6 \pm 0.9$ & $0.7 \pm 0.9$ & $0.5 \pm 0.9$ & 0.005 \\
\hline Sick day in the past year & & & & 0.085 \\
\hline More than once & $33(3.9 \%)$ & $21(4.0 \%)$ & $12(3.9 \%)$ & \\
\hline Once & $56(6.7 \%)$ & $43(8.1 \%)$ & $13(4.2 \%)$ & \\
\hline None & 749 (89.4\%) & $464(87.9 \%)$ & 285 (91.9\%) & \\
\hline $\begin{array}{l}\text { Dizziness or consciousness disorders associated with hypoglycemia } \\
\text { in the past year }\end{array}$ & & & & 0.074 \\
\hline Requested an ambulance or got the help of others & $8(1.0 \%)$ & $2(0.4 \%)$ & $6(1.9 \%)$ & \\
\hline Dealt with myself & $104(12.4 \%)$ & $68(12.9 \%)$ & $36(11.6 \%)$ & \\
\hline None & $726(86.6 \%)$ & $458(86.7 \%)$ & $268(86.5 \%)$ & \\
\hline
\end{tabular}

Note: *Comparisons by using $t$-test and $\chi^{2}$-test.

increased concentrations of blood glucose, which in turn influence glycemic control by eliciting other changes that reduce the blood glucose concentration. ${ }^{25-27}$ Additionally, HWB may enhance muscle glucose uptake. ${ }^{28,29}$

Recently, HSPs have been attracting attention for the pivotal role they play in glucose control. ${ }^{35}$ An increased amount of available HSP facilitates correct protein folding to prevent cell damage. Human and murine models of DM show low intracellular (i) and high extracellular (e) HSP levels that lead to a pro-inflammatory state that reduces insulin sensitivity. ${ }^{36,37}$ It is known that i-HSP has a proactive effect even if a high e-HSP status is linked with insulin resistance. ${ }^{38,39}$ It was reported that heating the body increased i-HSP levels in DM and in murine models. ${ }^{40-42}$ In addition, as heating the body changes the favorable ratio between i-HSP and e-HSP, and reduces insulin levels, it may also increase insulin signaling, improving glycemic control, and reducing insulin output by reducing inflammatory cytokines. ${ }^{43-49}$

\section{New Glycemic Control Based on a New Lifestyle During the COVID-19 Pandemic: External Validity}

Numerous epidemiological and clinical studies have been published on COVID-19 in 2020. In particular, several 
Table 3 Odds Ratio (95\% Confidence Interval) for Control of HbAlc According to Frequency and Duration of Daily Hot Water Bathing at Home $(\mathrm{N}=838)$

\begin{tabular}{|c|c|c|c|c|c|c|}
\hline Primary Explanatory Variables & Crude & $\begin{array}{l}P \text { for } \\
\text { Trend }\end{array}$ & $\begin{array}{l}\text { Model I } \\
\text { (Adjusted) }\end{array}$ & $\begin{array}{l}P \text { for } \\
\text { Trend }\end{array}$ & $\begin{array}{l}\text { Model } 2 \\
\text { (Adjusted) }\end{array}$ & $\begin{array}{l}P \text { for } \\
\text { Trend }\end{array}$ \\
\hline \multicolumn{7}{|c|}{$\begin{array}{l}\text { A: Frequency of daily hot water bathing at } \\
\text { home }\end{array}$} \\
\hline vs $\geq 7$ times/week & 1.0 (ref.) & 0.008 & I.0 (ref.) & 0.041 & I.0 (ref.) & 0.138 \\
\hline 4-6 times/week & $1.37(0.92-2.04)$ & & $1.32(0.87-1.99)$ & & $1.37(0.88-2.12)$ & \\
\hline$\leq 3$ times/week & $1.58(1.10-2.27)$ & & $1.43(0.98-2.10)$ & & $1.29(0.85-1.97)$ & \\
\hline \multicolumn{7}{|c|}{$\begin{array}{l}\text { B: Duration of daily hot water bathing at } \\
\text { home }\end{array}$} \\
\hline vs $>15$ min. & $\mathrm{I} .0$ (ref.) & 0.208 & 1.0 (ref.) & 0.413 & 1.0 (ref.) & 0.464 \\
\hline $5-15 \mathrm{~min}$ & $1.20(0.85-1.70)$ & & $1.20(0.83-1.72)$ & & $1.25(0.85-1.84)$ & \\
\hline$<5$ min. or only showering & $1.286(0.87-1.90)$ & & $1.19(0.80-1.79)$ & & $1.19(0.77-1.83)$ & \\
\hline
\end{tabular}

Notes: Model I. Covariates included sex, age, BMI, and T2DM duration. Model 2. Covariates included sex, age, BMI, T2DM duration, alcohol consumption, meal modification, smoking, exercise, drugs, and symptoms.

papers have focused on DM because it is a significant risk factor for complications from COVID-19 infection. . $^{7,50,51}$ Because it is difficult for T2DM patients to get out of the house in order to prevent infection, considerable concern exists that the various co-existing diseases and conditions of these patients will worsen. It has again been pointed out that it is necessary to shorten the sitting time and increase the amount of physical activity in patients with rheumatic diseases during periods of self-isolation. ${ }^{52}$ A single-center observational study in adolescents with T1DM reported that glycemic control did not worsen during the use of inhome physical activity (ie, a web-based exercise program) during quarantine. $^{53}$ During the COVID-19 pandemic, enhanced physical activity is essential not only to control DM but also obesity, heart disease, and high blood pressure; it is also expected to have positive effects on mental health. ${ }^{54,55}$

WB is considered to promote health in a highly safe and very low-cost manner, which is acceptable to many people in countries and regions where there is no traditional bathing culture. ${ }^{19,31,56-60}$ Bathing every day was found to be associated with self-rated good health and sleep quality. ${ }^{31}$ A single-arm intervention study outlined how a-12 day balneotherapy program improved pain, depression, mood, quality of life, and sleep in healthy elderly people. ${ }^{45}$ Moreover, the combination of exercise and HWB had a significant effect on pain relief and quality of life for patients with bone and joint diseases, especially those who were middle-aged and elderly. ${ }^{18-22}$ We expect that a combination of home-based exercise and HWB in T2DM patients is required to meet the crucial demand for a new lifestyle during and after COVID-19 self-isolation or quarantine.

However, the mechanism of action and effects of the proactive use of HWB in T2DM should be clarified by nonclinical tests, well-designed cohort studies, and randomized controlled trials.

\section{Limitations}

Despite being an innovative study, several methodological limitations exist. First, causality was not addressed since a mechanism of action by which HWB maintains good glycemic control could not be studied in a crosssectional study design. Second, sampling bias commonly occurs in cross-sectional studies. The population of participants in our study might have been ambiguous because the eligibility criteria for the medical institutions (types of hospitals and departments) were not defined, and only a short investigation period was used. Third, recall and response biases may have occurred in self-reports on bathing habits. Fourth, because other risks and confounding factors were not included as covariates in this study, additional important determinants of glycemic control might have been overlooked. Finally, the absence of a multiplied value for the frequency and duration of HWB, and the duration of exposure not being a variable, meant that the overall effectiveness of bathing was not fully elucidated.

\section{Conclusion}

In conclusion, a higher frequency of HWB was moderately associated with a decreased risk of poor glycemic control 
in middle-aged and elderly ambulatory patients with T2DM. However, the relationship between proactive use of HWB and a patient's health status should be clarified by well-designed cohort studies and randomized controlled trials.

\section{Highlights}

1. Our multicenter cross-sectional study is the first to explore the association of daily hot water bathing on glycemic control in middle-aged and elderly ambulatory patients with type 2 diabetes mellitus during a global COVID-19 pandemic.

2. Hot water bathing on a regular basis was moderately linked to a decreased risk of poor glycemic control.

3. The combination of hot water bathing and home-based exercise in patients is expected to meet the crucial demand for a new lifestyle during and after COVID19 self-isolation or quarantine.

\section{Data Sharing Statement}

No additional data are available.

\section{Ethical Approval}

The methodology of this study was approved by the Ethics Board of Tokyo University of Agriculture (No.1922 in 2020).

\section{Acknowledgments}

We received enormous cooperation from the Organization of Balneotherapists in the Japanese Association of Balneology, Climatology, and Physical Medicine (President: Dr. Norio Mitomo) for this research. We would like to take this opportunity to express our gratitude. And we would like to express our appreciation to all the doctors who cooperated: Dr. Kozo ASHIDA, Dr. Mitsuaki ARAKAWA, Dr. Miyoshi ITOH, Dr. Hiroki INOUE, Dr. Tatsuo IWASHITA, Dr. Koichiro OHMURA, Dr. Masaki OZAWA, Dr. Izumi ONO, Dr. Kan KATO, Dr. Mitsutoshi KATO, Dr. Kitaro KAWAMURA, Dr. Yoshio KODAMA, Dr. Yoshimasa GOTO, Dr. Shimmon GOMI, Dr. Kazuko SHIOZAWA, Dr. Atsushi SHITARA, Dr. Naoki SHIRAISHI, Dr. Takaaki SUGIMOTO, Dr. Misao TAKEUCHI, Dr. Eiichiro TANAKA, Dr. Shunichi NAGAI, Dr. Katsuhisa NISHI, Dr. Koutarou NISHIZAWA, Dr. Yasumasa NISHIYAMA, Dr. Kazuhiro MASUDA, Dr. Mihoko MATSUMURA, Dr. Takashi MIYAZAKI, Dr. Hironobu YAEGASHI, Dr. Naoto WATANABE, and Dr. Hiromi WATANABE. We are thankful for the generous assistance provided by Ms. Michiko Ishida (paper-work), Mr. Shun Nakamura (data collection and input), Dr. Jun Kitayuguchi (support of statistical analysis), and Ms. Mari Makishi (searches of studies).

\section{Author Contributions}

All authors made a significant contribution to the work reported, whether that is in the conception, study design, execution, acquisition of data, analysis and interpretation, or in all these areas; took part in drafting, revising or critically reviewing the article; gave final approval of the version to be published; have agreed on the journal to which the article has been submitted; and agree to be accountable for all aspects of the work.

\section{Funding}

This study was supported by the Japanese Society of Balneology, Climatology and Physical Medicine (President: Prof. Kazuhisa Miyashita) in 2019-2020. We would like to express our appreciation for their support.

\section{Disclosure}

The authors have no conflicts of interest to disclose for this work.

\section{References}

1. Danaei G, Finucane MM, Lu Y, et al. National, regional, and global trends in fasting plasma glucose and diabetes prevention surveys and epidemiological studies with 370 country-years and 2-7 million participants. Lancet. 2011;378(9785):31-40. doi:10.1016/S0140-6736(11) 60679-X

2. Lozano R, Naghavi M, Foreman F, et al. Global and regional mortality from 235 causes of death for 20 age groups in 1990 and 2010: a systematic analysis for the global burden of diseases study 2010. Lancet. 2012;380 (9859):2095-2128. doi:10.1016/S0140-6736(12)61728-0

3. Roglic G, Unwin N. Mortality attributable to diabetes: estimates for the year 2010. Diabetes Res Clin Pract. 2010;87(1):15-19. doi:10.1016/j.diabres.2009.10.006

4. International Diabetes Federation. IDF Diabetes Atlas. 7th ed. Brussels: Internation Diabetes Federation; 2015.

5. Magliano DJ, Islam RM, Barr ELM, et al. Trend in incidence of total or type 2 diabetes: systematic review. BMJ. 2019;366:I5003. doi:10.1136/bmj.I5003

6. Selvin E, Juraschek SP. Diabetes epidemiology in the COVID-19 Pandemic. Diabetes Care. 2020;43(8):1690-1694. doi:10.2337/dc201295

7. Richardson S, Hirsch JS, Narasimhan M, et al. Presenting characteristics, comorbidities, and outcomes among 5700 patients hospitalized with COVID-19 in the New York City area. JAMA. 2020;323 (20):2052-2059. doi:10.1001/jama.2020.6775

8. Roncon L, Zuin M, Rigatelli G, Zuliani G. Diabetic patients with COVID-19 infection are at higher risk of ICU admission and poor short-term outcome. J Clin Virol. 2020;127:104354. doi:10.1016/j. jcv.2020.104354 
9. Edler C, Schröder AS, Aepfelbacher M, et al. Dying with SARS-CoV -2 infection - an autopsy study of the first consecutive 80 cases in Hamburg, Germany. Int J Legal Med. 2020;134(4):1275-1284. doi:10.1007/s00414-020-02317-w

10. Ai-Khawaldeh OA, Ai-Hassan MA, Froelicher ES. Self-efficacy, self-management, and glycemic control with in adults with type 2 diabetes mellitus. $J$ Diabetes Complications. 2012;26(1):10-16. doi:10.1016/jjdiacomp.2011.11.002

11. Colagiuri S. Glycated haemoglobin (HbAlc) for the diagnosis of diabetes mellitus-practical implications. Diabetes Res Clin Pract. 2011;93:312-313. doi:10.1016/j.diabres.2011.06.025

12. American Diabetes Association. Standards of medical care in diabetes-2014. Diabetes Care. 2014;33(Suppl 1):S14-80. doi:10.2337/dc14-S014

13. Skyler JS, Bergenstal R, Bonow RO, et al. Intensive glycemic control and the prevention of cardiovascular events: implications of the ACCORD, ADVANCE, and VA diabetes trials: a position statement of the American Diabetes Association and a scientific statement of American College of Cardiology Foundation and the American Heart Association. $J$ Am Coll Cardiol. 2008;119:351-357. doi:10.1016/j.jacc.2008.10.008

14. American Diabetes Association. Standards of medical care in diabetes-2017. Diabetes Care. 2017;40(Suppl 1):S4-6. doi:10.2337/ dc17-S003

15. Diabetes Prevention Program Research Group. Reduction in the incidence of type 2 diabetes with lifestyle intervention or metformin. $N$ Engl J Med. 2002;346(6):393-403. doi:10.1056/ NEJMoa012512.

16. Norris SL, Lau J, Smith SJ, Schmid CH, Engelgau MM. Selfmanagement education for adults with type 2 diabetes: a meta-analysis of the effect on glycemic control. Diabetes Care. 2010;25(7):1159-1171. doi:10.2337/diacare.25.7.1159

17. Henstridge DC, Whitham M, Febbraio MA. Chaperoning to the metabolic party: the emerging therapeutic role of heat-shock proteins in obesity and type 2 diabetes. Mol Metab. 2014;3(8):781-793. doi:10.1016/j.molmet.2014.08.003

18. Antonelli M, Donelli D, Fioravanti A. Effects of balneotherapy and spa therapy on quality of life of patients with knee osteoarthritis: a systematic review and meta-analysis. Rheumatol Int. 2018;38 (10):1807-1824. doi:10.1007/s00296-018-4081-6

19. Kamioka H, Nobuoka S, Iijima J. Overview of systematic reviews with meta-analysis based on randomized controlled trials of balneotherapy and spa therapy from 2000 to 2019. Int J General Med. 2020;13:429-442. doi:10.2147/IJGM.S261820

20. Bai R, Li C, Xiao Y, Sharma M, Zhang F, Zhao Y. Effectiveness of spa therapy for patients with chronic low back pain: an updated systematic review and meta-analysis. Medicine (Baltimore). 2019;98 (37):e17092. doi:10.1097/MD.0000000000017092

21. de Moraes Silva MA, Nakano LC, Cisneros LL, Miranda F Jr. Balneotherapy for chronic venous insufficiency. Cochrane Database Syst Rev. 2019;26(8):CD013085. doi:10.1002/14651858.CD013085

22. Liang Z, Fu C, Zhang Q, et al. Effects of water therapy on disease activity, functional capacity, spinal mobility and severity of pain in patients with ankylosing spondylitis: a systematic review and meta-analysis. Disabil Rehabil. 2019;29:1-8. doi:10.1080/09638288.2019.1645218

23. Hooper PL. Hot-tub therapy for type 2 diabetes mellitus. $N$ Engl J Med. 1999;341(12):924-925. doi:10.1056/NEJM199909163411216

24. Brenner I, Shek PN, Zamecnik J, Shephard RJ. Stress hormones and the immunological responses to heat and exercise. Int J Sports Med. 1998;19(02):130-143. doi:10.1055/s-2007-971895

25. Jurcovicova J, Vigas M, Palat M, Jezova D, Klimes I. Effect of endogenous GH secretion during hyperthermic bath on glucose metabolism and insulin release in man. Endocrinol Exp. 1980;14:221-226.

26. Laatikainen T, Salminen K, Kohvakka A, Pettersson J. Response of plasma endorphins, prolactin and catecholamines in women to intense heat in a sauna. Eur J Appl Physiol Occup Physiol. 1988;57 (1):98-102. doi:10.1007/BF00691246
27. Strba'k V, Tata'r P, Angyal R, et al. Effects of sauna and glucose intake on TSH and thyroid hormone levels in plasma of euthyroid subjects. Metabolism. 1987;36(5):426-431. doi:10.1016/00260495(87)90038-2

28. Koshinaka K, Kawamoto E, Abe N, Toshinai K, Nakazato M, Kawanaka K. Elevation of muscle temperature stimulates muscle glucose uptake in vivo and in vitro. J Physiol Sci. 2013;63 (6):409-418. doi:10.1007/s12576-013-0278-3

29. Baron AD, Steinberg H, Brechtel G, Johnson A. Skeletal muscle blood flow independently modulates insulin-mediated glucose uptake. $\mathrm{Am}$ J Physiol. 1994;266:E248-253. doi:10.1152/ajpendo.1994.266.2.E248

30. Hooper PL, Balogh G, Rivas E, Kavanagh K, Vigh L. The importance of the cellular stress response in the pathogenesis and treatment of type 2 diabetes. Cell Stress Chaperones. 2014;19:447-464. doi:10.1007/s12192-014-0493-8

31. Hayasaka S, Shibata Y, Goto Y, Noda T, Ojima T. Bathing in a bathtub and health status: a cross-sectional study. Complement Ther Clin Pract. 2010;16(4):219-221. doi:10.1016/j.ctcp.2010.05.002

32. Kamioka H, Mori Y, Nagata K, Iwanaga S, Uzura M, Yamaguchi S. Relationship of daily hot water bathing at home and hot water spa bathing with underlying diseases in middle-aged and elderly ambulatory patients: a Japanese multicenter cross-sectional study. Complement Ther Med. 2019;43:232-239. doi:10.1016/j.ctim.2019.02.003

33. von Elm E, Altman DG, Egger M, Pocock SJ, Gøtzsche PC, Vandenbroucke JP. The strengthening the reporting of observational studies in epidemiology (STROBE) statement: guidelines for reporting observational studies. Ann Intern Med. 2007;147(8):573-577. doi:10.7326/0003-4819-147-8-200710160-00010

34. Kanda Y. Investigation of the freely available easy-to-use software "EZR" for medical statistics. Bone Marrow Transplant. 2013;48 (3):452-458. doi:10.1038/bmt.2012.244

35. Maley MJ, Hunt AP, Stewart IB, Faulkner SH, Minett GM. Passive heating and glycaemic control in nondiabetic and diabetic individuals: a systematic review and meta-analysis. PLoS One. 2019;14: e021422. doi:10.1371/journal.pone. 0214223

36. Hooper PL, Hooper PL. Inflammation, heat shock proteins, and type 2 diabetes. Cell Stress Chaperones. 2009;14(2):113-115. doi:10.1007/ s12192-008-0073-x

37. Habich C, Sell H, Burkart V. Regulatory role of heat shock proteins in the pathogenesis of type 1 and type 2 diabetes. Curr Immunol Rev. 2017;82-90.

38. Krause M, Bock PM, Takahashi HK. The regulatory roles of NADPH oxidase, intra- and extra-cellular HSP70 in pancreatic islet function, dysfunction and diabetes. Clin Sci. 2015;128:789-803.

39. Molina MN, Ferder L, Manucha W. Emerging role of nitric oxide and heat shock proteins in insulin resistance. Curr Hypertens Rep. 2016;18(1):1. doi:10.1007/s11906-015-0615-4

40. Chung J, Nguyen A-K-K, Henstridge DC, et al. HSP72 protects against obesity-induced insulin resistance. Proc Natl Acad Sci U S A. 2008;105(5):1739-1744. doi:10.1073/pnas.0705799105

41. Simar D, Jacques A, Caillaud C. Heat shock proteins induction reduces stress kinases activation, potentially improving insulin signaling in monocytes from obese subjects. Cell Stress Chaperones. 2012;17(5):615-621. doi:10.1007/s12192-012-0336-4

42. Gupte AA, Bomhoff GL, Swerdlow RH, Geiger PC. Heat treatment improves glucose tolerance and prevents skeletal muscle insulin resistance in rats fed a high-fat diet. Diabetes. 2009;58:567LP-578.

43. Krause M, Heck TG, Bittencourt A, et al. The chaperone balance hypothesis: the importance of the extracellular to intracellular HSP70 ratio to inflammation-driven type 2 diabetes, the effect of exercise, and the implications for clinical management. Mediators Inflamm. 2015;249205.

44. Hirosumi J, Tuncman G, Chang L, et al. A central role for JNK in obesity and insulin resistance. Nature. 2002;420(6913):333-336. doi:10.1038/nature01137 
45. Yuan M, Konstantopoulos N, Lee J, et al. Reversal of obesity- and diet-induced insulin resistance with salicylates or targeted disruption of ikkbeta. Science. 2001;293(5535):1673-1677. doi:10.1126/science.106 1620

46. Archer AE, Von Schulze AT, Geiger PC. Exercise, heat shock proteins and insulin resistance. Philos Trans $R$ Soc Lond B Biol Sci. 2018;373(1738):20160529. doi:10.1098/rstb.2016.0529

47. Kokura S, Adachi S, Manabe E, et al. Whole body hyperthermia improves obesity-induced insulin resistance in diabetic mice. Int J Hyperth. 2007;23(3):259-265. doi:10.1080/02656730601176824

48. Bathaie SZ, Jafarnejad A, Hosseinkhani S, Nakhjavani M. The effect of hot-tub therapy on serum Hsp70 level and its benefit on diabetic rats: a preliminary report. Int $J$ Hyperth. 2010;26(6):577-585. doi:10.3109/02656736.2010.485594

49. Gupte AA, Bomhoff GL, Touchberry CD, Geiger PC. Acute heat treatment improves insulin-stimulated glucose uptake in aged skeletal muscle. J Appl Physiol. 2011;110(2):451-457. doi:10.1152/ japplphysiol.00849.2010

50. Kumar A, Arora A, Sharma P, et al. Is diabetes mellitus associated with mortality and severity of COVID-19? A meta-analysis. Diabetes Metab Syndr. 2020;14(4):535-545. doi:10.1016/j.dsx.2020.04.044

51. Targher G, Mantovani A, Wang XB, et al. Patients with diabetes are higher risk for severe illness from COVID-19. Diabetes Metab. 2020;46(4):335-337. doi:10.1016/j.diabet.2020.05.001

52. Pinto AJ, Dunston DW, Owen N, Bonfa E, Gualano B. Combating physical inactivity during the COVID-19 pandemic. Nat Rev Rheumatol. 2020;16(7):347-348. doi:10.1038/s41584-020-0427-z

53. Tornese G, Ceconi V, Monasta L, Carletti C, Faleschini E, Barbi E. Glycemic control in type 1 diabetes mellitus during COVID-19 quarantine and the role of in-home physical activity. Diabetes Technol Ther. 2020;22(6):462-467. doi:10.1089/dia.2020.0169
54. Dwyer MJ, Pasini M, Dominicis SD, Rihi E. Physical activity: benefits and challenges during the COVID-19 pandemic. Scand J Med Sci Sports. 2020;30(7):1291-1294. doi:10.1111/sms.13710

55. Callow DD, Arnold-Nedimala NA, Jourdan LS, et al. The mental health benefits of physical activity in older adults survive the COVID-19 pandemic. Am J Geriatr Psychiatry. 2020;28 (10):1046-1057. doi:10.1016/j.jagp.2020.06.024

56. Gremeaux V, Benaïm C, Poiraudeau S, Hérisson C, Dupeyron A, Coudeyre E. Evaluation of the benefits of low back pain patients' education workshops during spa therapy. Joint Bone Spine. 2013;80 (1):82-87. doi:10.1016/j.jbspin.2011.12.014

57. Ciprian L, Lo Nigro A, Rizzo M, et al. The effects of combined spa therapy and rehabilitation on patients with ankylosing spondylitis being treated with TNF inhibitors. Rheumatol Int. 2013;33 (1):241-245. doi:10.1007/s00296-011-2147-9

58. Fioravanti A, Giannitti C, Bellisai B, Iacoponi F, Galeazzi M. Efficacy of balneotherapy on pain, function and quality of life in patients with osteoarthritis of the knee. Int J Biometeorol. 2012;56 (4):583-590. doi:10.1007/s00484-011-0447-0

59. Ozkurt S, Dönmez A, Zeki Karagülle M, Uzunoğlu E, Turan M, Erdoğan N. Balneotherapy in fibromyalgia: a single blind randomized controlled clinical study. Rheumatol Int. 2012;32(7):1949-1954. doi:10.1007/s00296-011-1888-9

60. Latorre-Roman PA, Rentero-Blanco M, Laredo-Agulilera JA, GarciaPinillos F. Effect of a 12-day balneotherapy programme on pain, mood, sleep, and depression in healthy elderly people. Psychogeriatrics. 2015;15(1):14-19. doi:10.1111/psyg.12068

\section{Publish your work in this journal}

Diabetes, Metabolic Syndrome and Obesity: Targets and Therapy is an international, peer-reviewed open-access journal committed to the rapid publication of the latest laboratory and clinical findings in the fields of diabetes, metabolic syndrome and obesity research. Original research, review, case reports, hypothesis formation, expert opinion and commentaries are all considered for publication. The manuscript management system is completely online and includes a very quick and fair peer-review system, which is all easy to use. Visit http://www.dovepress.com/testimonials.php to read real quotes from published authors. 